\title{
PENGARUH PERCEIVED EASE-OF-USE, PERCEIVED USEFULNESS, TRUST DAN PERCEIVED ENJOYMENT TERHADAP REPURCHASE INTENTION (STUDI KASUS PADA WEBSITE ZALORA INDONESIA)
}

\author{
INDAH PUSPITASARI \\ VITA BRILIANA
}

\author{
Trisakti School of Management \\ indahpuspitasari0701@gmail.com \\ vita@stietrisakti.ac.id
}

\begin{abstract}
The purpose of this research is to know the influence of perceived ease of use, perceived usefulness, trust, and enjoyment with repurchase intention at Zalora Indonesia. The research design used in descriptive research and causality research. The population of this research is customers of Zalora Indonesia. The sampling in the study was purposive sampling and uses 100 responded. The respondents of this study were women who make online purchases through the website www.zalora.co.id. Data were analyzed using multiple regression analysis. The result showed that there is an influence among perceived ease of use, perceived usefulness, trust, and perceived enjoyment with repurchase intention at Zalora Indonesia.
\end{abstract}

Keywords: perceived ease of use, perceived usefulness, trust, perceived enjoyment, repurchase intention

\begin{abstract}
Abstrak: Tujuan penelitian untuk mengetahui pengaruh persepsi kemudahan penggunaan, persepsi kegunaan, kepercayaan, dan kesenangan yang dirasakan terhadap niat pembelian kembali di Zalora Indonesia. Desain penelitian yang digunakan penelitian deskriptif dan penelitian kausalitas. Populasi dalam penelitian ini adalah pelanggan Zalora Indonesia. Menggunakan teknik purposive sampling dengan 100 responden, berkriteria wanita yang pernah melakukan belanja online melalui situs web www.zalora.co.id. Data dianalisis menggunakan analisis regresi berganda. Hasil penelitian menunjukkan bahwa ada pengaruh persepsi kemudahan penggunaan, persepsi kegunaan, kepercayaan, dan kesenangan yang dirasakan terhadap niat pembelian kembali di Zalora Indonesia.
\end{abstract}

Kata kunci: persepsi kemudahan penggunaan, persepsi kegunaan, kepercayaan, kesenangan yang dirasakan, niat pembelian kembali 


\section{PENDAHULUAN}

Pembelian ulang atau loyalitas konsumen sangat penting untuk kesuksesan dan keuntungan toko online. Dengan adanya hal ini, maka dimanfaatkan oleh para ecommerce. E-commerce adalah proses membeli dan menjual produk secara elektronik oleh konsumen dan dari perusahaan ke perusahaan dengan komputer dan internet sebagai perantara transaksi bisnis. Fenomena di Jakarta, 24/7 smartphone yang maksudnya 24 jam dalam 7 hari orang Indonesia mayoritas menghabiskan waktu untuk terkoneksi dengan media sosial (seperti Facebook, Instagram dan sebagainya) kapanpun dan di manapun serta aktivitas browsing di internet untuk berbagai kebutuhan (Briliana 2017). Netizen menggunakan teknologi browsing di internet untuk berbagai kebutuhan, seperti mencari, membeli pakaian, dan menyelesaikan transaksi pembelian mereka dengan mudah. Bagi pengecer, mereka hanya perlu menampilkan beberapa contoh pakaian mereka, daripada mengeluarkan biaya untuk mendirikan toko pakaian lengkap (Briliana 2016).

Hasil penelitian APJII 2017 dipublikasikan tahun 2018 dengan 2.500 responden dari seluruh Indonesia menyatakan bahwa dari penduduk Indonesia sejumlah 262 juta orang sebanyak 143,26 juta adalah mereka pengguna internet dengan $87.13 \%$ mereka mengaku terkoneksi sosial media dan 32,18\% pernah belanja online. Berdasarkan Marketeer artikel yang dipublikasikan pada 15 September 2016, Zalora memposisikan diri sebagai destinasi fesyen online terbesar di ASEAN. Zalora semakin memantapkan langkahnya di sektor e-commerce. Zalora merupakan ecommerce khusus fesyen yang didirikan sejak tahun 2012 lalu. Zalora telah melayani pasar Asia Tenggara, seperti Indonesia, Singapura, Malaysia, Brunei, Filipina, Thailand, Vietnam, dan Hong Kong. Di Indonesia Zalora menetapkan umur 18 tahun sebagai batasannya umur untuk dapat berbelanja secara online di Zalora. Dibawah umur 18 tahun harus melibatkan orangtua atau wali. Dan juga segmentasi Zalora adalah untuk kalangan menengah keatas, seperti untuk mahasiswa, first jobber, ataupun ibu rumah tangga, dengan kategori 20 - 35 tahun. Menurut penelitian yang dilakukan Briliana dan Mursito (2017) menyatakan bahwa jumlah wanita yang tinggal diperkotaan dan merupakan kelompok menengah keatas diperkirakan sebanyak 35 juta orang merupakan pasar potensial untuk e-commerce salah satunya produk yang ditawarkan Zalora.

Penelitian ini bertujuan untuk menjawab pertanyaan apakah perceived ease-of-use (persepsi akan kemudahan), perceived usefulness (persepsi akan kemanfaatan), trust (kepercayaan), dan perceived enjoyment (kesenangan yang dirasakan) memberikan pengaruh terhadap repurchase intention (niat membeli kembali) konsumen Zalora Indonesia. Penelitian ini juga dapat memberikan manfaat bagi perusahaan sebagai bahan masukan kepada perusahaan dalam mengelola dan meningkatkan kepuasan pembeli melalui perceived ease-of-use, perceived usefulness, trust, dan perceived enjoyment

\section{Pengaruh Perceived Ease-of-Use Terhadap Repurchase Intention}

Perceived ease-of-use mengacu pada sejauhmana konsumen percaya bahwa dengan belanja online lebih mudah (Chao et al.,2009). Menurut Malhotra (2010:740) perceived easeof-use didefinisikan sebagai "the degree to which the person will find it easy to use the technology application when they consider using it." Disimpulkan bahwa perceived easeof-use adalah tingkat sejauhmana konsumen percaya bahwa belanja online akan bebas dari usaha dan mudah untuk digunakan. Penelitian yang dilakukan sebelumnya oleh Chao et al., (2009) menyatakan bahwa pengaruh perceived ease-of-use lebih tinggi dibandingkan perceived usefulness dan Enjoyment. Peningkatan persepsi akan kemudahan mengarah pada 
peningkatan kinerja, kemudahan penggunaan akan bersifat langsung pengaruhnya pada persepsi akan kemanfaatan dan niat membeli (Venkatesh dan Davis 2000).

\section{Pengaruh Perceived Usefulness Terhadap Repurchase Intention}

Menurut Davis et al., (1989) perceived usefulness adalah "the degree to which a person believes that using a particular system would enhance his or her job performance." Penelitian Babin et. al (2001) menyatakan pelanggan yang telah menyelesaikan tugas belanja untuk memperoleh produk dengan cara yang efisien akan lebih cenderung menunjukkan niat membeli kembali yang lebih kuat. Apabila konsumen memiliki kemampuan untuk menggunakan aplikasi teknologi yang dirasakan maka hal itu dapat membantunya mencari produk/jasa yang diinginkan dengan mudah (Rajalie dan Briliana 2014). Disimpulkan perceived usefulness adalah suatu tingkat atau sejauhmana konsumen percaya bahwa belanja online akan meningkatkan kinerja mereka. Penelitian yang dilakukan oleh Cyr et al. (2006) menyatakan persepsi akan kemanfaatan berpengaruh terhadap niat membeli kembali.

\section{Pengaruh Trust Terhadap Repurchase Intention}

Trust didefinisikan oleh Kotler and Keller (2016:231) sebagai "A firm's willingness to rely on a business partner. It depends on a number of interpersonal and interorganizational factors, such as the firm's perceived competence, integrity, honesty, and benevolence." Kepercayaan pelanggan akan kemanjuran dan keandalan merek (Clow and Baack 2016). Menurut Pavlou and Fygenson dalam Chao et al. (2009) bahwa keyakinan pembeli kepada penjual dikarenakan berperilaku baik hati, cakap dan etis. Kesimpulan trust adalah kemauan seseorang untuk bertumpu pada orang lain, dimana kita memiliki keyakinan padanya. Penelitian Wen et al. (2011) menyatakan bahwa semakin tinggi kepercayaan maka semakin tinggi niat membeli kembali. Dalam proses shopping online, kepercayaan memegang peranan penting diantaranya memberikan rasa kepercayaan kepada konsumen baik dalam hal privasi maupun kualitas produk yang ditawarkan (Rajalie dan Briliana, 2014).

\section{Pengaruh Perceived Enjoyment Terhadap Repurchase Intention}

Menurut Deci dalam Chao et al., (2009) "Enjoyment is an effective response and an intrinsic motivation that refers to the performance of an activity for no apparent reinforcement other than the process of performing it". Penelitian Davis et al. (1989) menyatakan kesenangan yang dirasakan memiliki pengaruh langsung terhadap niat perilaku. Disimpulkan bahwa perceived enjoyment (kesenangan yang dirasakan) adalah sejauhmana persepsi seseorang dapat merasakan puas dan senang akan sesuatu yang didapatkannya. Temuan yang dihasilkan dari penelitian Rajalie dan Briliana (2014) menunjukkan bahwa semakin tinggi persepsi akan kesenangan yang dirasakan semakin tinggi pula niat membeli kembali. Hasil penelitian yang dilakukan oleh Koufaris (2002), dan Bart et al. (2005) menyatakan bahwa kesenangan yang dirasakan berpengaruh kepada niat membeli kembali.

\section{Repurchase Intention}

Keinginan membeli kembali mengacu pada penilaian individu tentang membeli lagi layanan yang ditunjuk dari perusahaan yang sama, dengan mempertimbangkan situasi saat ini dan berbagai kemungkinan (Lacey dan Morgan, 2009). Serangkaian tindakan lain yang terkait erat dengan sikap dan pertimbangan merek (Keller, 2013). Purchase intention mengukur kecenderungan konsumen untuk membeli sebuah merek atau berpindah ke merek lain. Menurut Chao et al., (2009) perilaku niat membeli kembali mengacu pada probabilitas subjektif bahwa seseorang akan 
terus membeli produk dari vendor atau toko online dimasa depan. Disimpulkan repurchase intention adalah keputusan terencana seseorang untuk melakukan pembelian kembali atas jasa dan produk tertentu, dengan mempertimbangkan situasi yang terjadi dan tingkat kesukaan.

Hipotesis bertujuan mengarahkan dan memberikan dasar dalam pokok permasalahan serta tujuan penelitian. Ditetapkan hipotesis penelitian sebagai berikut:

$\mathrm{H}_{1}$ : Perceived ease of use mempengaruhi repurchase intention pada konsumen Zalora Indonesia.

$\mathrm{H}_{2}$ : Perceived usefulness mempengaruhi repurchase intention pada konsumen Zalora Indonesia.

$\mathrm{H}_{3}$ : Trust mempengaruhi repurchase intention pada konsumen Zalora Indonesia

$\mathrm{H}_{4}$ : Perceived enjoyment mempengaruhi repurchase intention pada konsumen Zalora Indonesia.

\section{METODA PENELITIAN}

Penelitian kausal merupakan riset yang diadakan untuk menguji dan membuktikan suatu hubungan sebab akibat (Causal Effect). Menurut Sekaran dan Bougie (2016:44) A study in which the researcher wants to delineate one or more factors that are causing the problem. Tujuan dari riset kausal adalah untuk memahami variabel mana yang menjadi penyebab dan variable mana yang terkena efek (terkait).

\section{Populasi dan Sampel}

Untuk penelitian ini populasi yang digunakan adalah konsumen Zalora. Sedangkan jumlah sampel yang digunakan dalam penelitian ini adalah 100. Dengan mengacu pada pendapat yang dikemukakan oleh Hair et al. $(2014,100)$ maka jumlah ini cukup representatif untuk digunakan dalam teknik analisis regresi. Metoda pengambilan sampel dengan menggunakan teknik purposive sampling. yakni teknik penentuan sampel dengan pertimbangan tertentu Sugiyono (2016:144). Obyek dalam penelitian ini adalah website online yaitu http://www.zalora.co.id/. Responden dalam penelitian adalah wanita yang pernah membeli fashion melalui website www.zalora.co.id dengan kriteria sebagai berikut: responden wanita, berumur diatas 18 tahun, memiliki dan rutin mengakses internet, pernah melakukan pembelian pada situs website www.zalora.co.id dalam sebulan terakhir. Pernyataan-pernyataan disiapkan dalam kuesioner terstruktur dengan menggunakan skala 1- 5 dari sangat tidak setuju sampai sangat setuju. Dengan kemajuan teknologi, survei pada penelitian kali ini dilakukan dengan google survey dan disampaikan melalui What's App messenger, email, Facebook dan media lainnya yang memungkinkan. Disebarkan ke 125 responden dan sebanyak 100 responden yang merespon dan bisa digunakan artinya respon rate sebesar $80 \%$ dan konsisten dengan temuan yang dihasilkan dari penelitian yang dilakukan oleh Janet Wagner dan Gabrielle Rydstrom (2011) yang melakukan penelitian tentang bagaimana konsumen melihat hubungan diantara mereka dengan retail online, survey mereka lakukan melalui email yang dikirim secara random dengan sampel 1000 pelanggan toko online di Amerika dengan tingkat tanggapan mencapai $32 \%$ (320) konsumen yang menanggapinya. $\mathrm{Hal}$ ini memperkuat justifikasi kebiasaan pemilihan responden yang memiliki motivasi, kemampuan, dan peluang terhubung dengan internet untuk belanja online (Briliana et al. 2015)

\section{HASIL PENELITIAN}

Berdasarkan hasil pengolahan kuisioner, maka karakteristik responden konsumen Zalora di sebagai berikut: 
Tabel 1 Karakteristik Responden

\begin{tabular}{llr} 
Keterangan & & Jumlah \\
\hline Usia & 18 - 20 tahun & 18 \\
& 21-23 tahun & 72 \\
& 24 - 26 tahun & 3 \\
& 27 - 29 tahun & 2 \\
& $\geq 30$ Tahun & 5 \\
\hline Pekerjaan & Ibu Rumah Tangga & 1 \\
& Kuliah dan Bekerja & 66 \\
& Pegawai Negeri/Pegawai Swasta & 17 \\
& Pelajar/Mahasiswa & 13 \\
& Wiraswasta & 3 \\
\hline Frekuensi belanja & 1 kali & 13 \\
Dalam sebulan & 2 kali & 59 \\
terakhir & 4 kali & 28 \\
\hline Harga barang & Rp. 100.000 - Rp.250.000 & 54 \\
terakhir yang & Rp. 250.001 - Rp.500.000 & 28 \\
dibeli di Zalora & Rp. 500.001 - Rp.750.000 & 11 \\
& $>$ Rp. 750.001 & 7 \\
\hline
\end{tabular}

Sumber : Data primer yang sudah diolah (2017).

\section{Pengujian Validitas dan Reliabilitas}

Uji validitas digunakan untuk menguji keabsahan dari kuesioner yang digunakan untuk mengukur suatu variabel.

Tabel 2 Hasil Pengujian Validitas dan Reliabilitas

\begin{tabular}{lcccc}
\hline Variabel & $\begin{array}{c}\text { Measurement } \\
\text { Items }\end{array}$ & $\begin{array}{c}r \\
\text { hitung }\end{array}$ & $\begin{array}{c}\text { r tabel } \\
\text { [df=n-(k+1)] }\end{array}$ & $\begin{array}{c}\text { Cronbach } \\
\text { Alpha }(\alpha)\end{array}$ \\
\hline perceived & PEOU1 & 0,784 & 0,196 & 0,870 \\
ease of use & PEOU2 & 0,559 & & \\
$\left(\mathrm{X}_{1}\right)$ & PEOU3 & 0,671 & & \\
& PEOU4 & 0,695 & & \\
& PEOU5 & 0,776 & & 0,886 \\
perceived & PU1 & 0,634 & 0,196 & \\
usefulnes & PU2 & 0,766 & & \\
$\left(\mathrm{X}_{2}\right)$ & PU3 & 0,841 & & \\
& PU4 & 0,657 & & 0,905 \\
& PU5 & 0,743 & & \\
trust & T1 & 0,710 & 0,196 & \\
$\left(\mathrm{X}_{3}\right)$ & T2 & 0,779 & &
\end{tabular}




\begin{tabular}{lllll} 
& T3 & 0,635 & & \\
& T4 & 0,797 & & \\
& T5 & 0,764 & & \\
\hline perceived & E1 & 0,772 & 0,196 & 0,891 \\
enjoyment & E2 & 0,830 & & \\
$\left(X_{4}\right)$ & E3 & 0,756 & & \\
\hline repurchase & RI1 & 0,610 & 0,196 & 0,730 \\
intention & RI2 & 0,485 & & \\
$(Y)$ & RI3 & 0,568 & & \\
\hline
\end{tabular}

Sumber : Data primer yang sudah diolah (2017).

Berdasarkan tabel 2, dapat disimpulkan bahwa semua item indikator dinyatakan valid karena nilai $r$ hitung lebih besar daripada nilai $r$ tabel yaitu lebih besar dari 0,197. Sekaran dan Bougie (2016, 290) menyatakan bahwa pengujian reliabilitas dapat dilakukan dengan membandingkan hasil cronbach alpha dengan 0,60 sebagai batasannya. Hasil uji reliabilitas sesuai tabel diatas menunjukkan bahwa semua variabel mempunyai koefisien Alpha yang cukup besar yaitu diatas 0,60 , sehingga disimpulkan bahwa masing-masing variabel dari kuesioner adalah reliabel.

\section{Uji Normalitas}

Tujuannya untuk mengetahui apakah dalam sebuah model regresi, variabel independen dan dependen berdistribusi normal atau tidak. Salah satu syarat untuk menggunakan statistik parametrik adalah berdistribusi normal. Pengujian dengan metode non-grafik yaitu dengan menguji nilai skewness dan kurtosis. Nilai $Z$ hitung tersebut dibandingkan dengan nilai kritis untuk significant level $5 \%$ sebesar $\pm 1,96$ yaitu $-1,96$ sampai $+1,96$

Tabel 3 Hasil Uji Skewness dan Kurtosis

\begin{tabular}{lccc}
\hline & $N$ & Skewness & Kurtosis \\
\cline { 2 - 4 } & Statistic & Statistic & Statistic \\
\hline Perceived Ease of Use $\left(\mathrm{X}_{1}\right)$ & 100 & $-0,098$ & $-0,768$ \\
Perceived Usefulness $\left(\mathrm{X}_{2}\right)$ & 100 & $-0,386$ & $-0,515$ \\
Trust $\left(\mathrm{X}_{3}\right)$ & 100 & $-0,306$ & 0,487 \\
Perceived Enjoyment $\left(\mathrm{X}_{4}\right)$ & 100 & $-0,176$ & -0.506 \\
Repurchase Intention $(\mathrm{Y})$ & 100 & 0,167 & $-0,646$ \\
\hline
\end{tabular}

Sumber : Data primer yang sudah diolah (2017). 
Tabel 4 Hasil Hitung Skewness

\begin{tabular}{|c|c|c|c|}
\hline & Skewness & Hasil Z & \multirow{2}{*}{ Kesimpulan } \\
\hline & $\sqrt{6 / n}$ & Skewness & \\
\hline \multirow{2}{*}{ Perceived Ease of Use (X1) } & $-0,098$ & \multirow{2}{*}{$-0,401$} & \multirow{2}{*}{ Berdistribusi Normal } \\
\hline & 0,244 & & \\
\hline \multirow{2}{*}{ Perceived Usefulness (X2) } & $-0,386$ & \multirow{2}{*}{$-1,582$} & \multirow{2}{*}{ Berdistribusi Normal } \\
\hline & 0,244 & & \\
\hline \multirow{2}{*}{ Trust (X3) } & $-0,306$ & \multirow{2}{*}{$-1,254$} & \multirow{2}{*}{ Berdistribusi Normal } \\
\hline & 0,244 & & \\
\hline \multirow{2}{*}{ Perceived Enjoyment (X4) } & $-0,176$ & \multirow{2}{*}{$-0,721$} & \multirow{2}{*}{ Berdistribusi Normal } \\
\hline & 0,244 & & \\
\hline \multirow{2}{*}{ Repurchase Intention (Y) } & 0,167 & \multirow{2}{*}{0,684} & \multirow{2}{*}{ Berdistribusi Normal } \\
\hline & 0,244 & & \\
\hline
\end{tabular}

Sumber : Data primer yang sudah diolah (2017).

Tabel 5 Hasil Uji Kurtosis

\begin{tabular}{|c|c|c|c|}
\hline & Kurtosis & Hasil Z & Kecimnulan \\
\hline & $\sqrt{24 / n}$ & & Nesinipuran \\
\hline \multirow{2}{*}{ Perceived Ease of Use (X1) } & $-0,768$ & \multirow{2}{*}{$-1,570$} & \multirow{2}{*}{ Berdistribusi Norma } \\
\hline & 0,489 & & \\
\hline \multirow{2}{*}{ Perceived Usefulness (X2) } & $-0,515$ & \multirow{2}{*}{$-1,053$} & \multirow{2}{*}{ Berdistribusi Norma } \\
\hline & 0,489 & & \\
\hline \multirow{2}{*}{ Trust (X3) } & $-0,487$ & \multirow{2}{*}{$-0,996$} & \multirow{2}{*}{ Berdistribusi Normal } \\
\hline & 0,489 & & \\
\hline \multirow{2}{*}{ Perceived Enjoyment (X4) } & $-0,506$ & \multirow{2}{*}{$-1,035$} & \multirow{2}{*}{ Berdistribusi Normal } \\
\hline & 0,489 & & \\
\hline \multirow{2}{*}{ Repurchase Intention (Y) } & 0,646 & \multirow{2}{*}{1,321} & \multirow{2}{*}{ Berdistribusi Normal } \\
\hline & 0,489 & & \\
\hline
\end{tabular}

Sumber : Data primer yang sudah diolah (2017).

Berdasarkan tabel 4 dan 5, nilai Zskewness dan Zkurtosis berada diantara nilai Z tabel $\pm 1,96$. Sehingga dapat disimpulkan dari pengujian metode grafik pada gambar Normal P-P Plot dan perhitungan nilai Skewness dan Kurtosis, pengujian data berdistribusi normal.

\section{Pengujian Regresi linier}

Analisis regresi linier berganda digunakan untuk menguji perceived ease-of-use, perceived usefulness, trust dan perceived enjoyment memberikan pengaruh terhadap repurchase intention. 
Tabel 6 Hasil Analisis Regresi Berganda

\begin{tabular}{|c|c|c|c|c|c|c|}
\hline \multirow{2}{*}{ Model } & & \multicolumn{2}{|c|}{$\begin{array}{c}\text { Unstandardized } \\
\text { Coefficients }\end{array}$} & \multirow{2}{*}{$\begin{array}{c}\begin{array}{c}\text { Standardized } \\
\text { Coefficients }\end{array} \\
\text { Beta }\end{array}$} & \multirow[b]{2}{*}{$\mathrm{t}$} & \multirow[b]{2}{*}{ Sig. } \\
\hline & & B & Std. Error & & & \\
\hline \multirow{5}{*}{1} & (Constant) & 3.680 & 1.056 & & 3.484 & .001 \\
\hline & PEOU & .107 & .080 & .161 & 1.345 & .182 \\
\hline & PU & -.040 & .071 & -.071 & -.558 & .578 \\
\hline & Trust & .140 & .067 & .304 & 2.079 & .040 \\
\hline & PE & .293 & .114 & .341 & 2.575 & .012 \\
\hline
\end{tabular}

a. Dependent Variable: RI

Sumber : Data primer yang diolah, 2017

Dari hasil tersebut maka persamaan regresi dalam bentuk standardized coefficient sebagai berikut:

$Y=3,680+0,107 X_{1}-0,040 X_{2}+0,140 X_{3}+0,293 X_{4}$

Dimana :

$\mathrm{Y}=$ repurchase Intention

$\mathrm{a}=$ konstanta

$\mathrm{X}_{1}=$ perceived ease of use

$\mathrm{X}_{2}=$ perceived usefulness

$\mathrm{X}_{3}=$ trust

$\mathrm{X}_{4}=$ perceived enjoyment

Berdasarkan persamaan regresi diatas menyatakan bahwa variabel perceived ease-ofuse, perceived usefulness, trust dan perceived enjoyment berpengaruh terhadap repurchase intention.
Uji Kelayakan Suatu Model (Goodness of Fit) Ketetapan fungsi regresi dalam menaksir nilai actual dapat diukur dari Goodness of Fitnya, dan dapat diukur dengan nilai $F$, uji t, dan nilai koefisien determinasi. Digunakan untuk menguji signifikansi ada tidaknya pengaruh variabel bebas (independen) terhadap variabel terikatnya (dependen). Berdasarkan hasil uji $\mathrm{F}$ pada tabel ANOVA (tabel 7) diperoleh $\mathrm{F}$ hitung sebesar 20.864 dengan tingkat signifikansi 0,000 . $F$ hitung $>F$ tabel (20.864 lebih besar dari 2,46) dan tingkat signifikansi $0,000<0,05$ maka model regresi dapat digunakan untuk memprediksi repurchase intention $(Y)$ atau variabel perceived ease of use $\left(X_{1}\right)$, perceived usefulness $\left(X_{2}\right)$, trust $(X 3)$, dan perceived enjoyment $(X 4)$ terhadap repurchase intention $(\mathrm{Y})$.

Tabel 7 Hasil Uji F

\begin{tabular}{lccccc}
\hline Model & Sum of Squares & df & Mean Square & $F$ & Sig. \\
& & & & & \\
\hline Regression & 146.336 & 4 & 36.584 & 20.864 & $.000^{\mathrm{b}}$ \\
1 Residual & 166.574 & 95 & 1.753 & & \\
$\quad$ Total & 312.910 & 99 & & & \\
\hline $\begin{array}{l}\text { Dependent Variable: RI } \\
\text { Sumber : Data primer yang diolah, } 2017\end{array}$ & & & & \\
\end{tabular}


Untuk mengetahui signifikansi pengaruh variabel bebas secara individual menerangkan variabel terikat.

Tabel 8 Hasil Uji t

\begin{tabular}{lcc}
\hline \hline \multicolumn{1}{c}{ Variabel Bebas } & t-value & Sig. \\
\hline \hline Perceived ease of use & 6,758 & .000 \\
Perceived usefulness & 6,061 & .000 \\
Trust & 8,316 & .000 \\
perceived enjoyment & 8,251 & .000 \\
\hline \hline
\end{tabular}

Sumber : Data primer yang diolah, 2017

Hasil analisis Uji t antara lain:

a. Nilai t hitung pada variabel perceived ease of use $\left(X_{1}\right)$ adalah sebesar 6,758 dengan tingkat signifikansi 0,000 . t hitung lebih besar dari $t$ tabel yakni $(6,758>1.985)$ dan nilai signifikansi $0,000<0,05$ maka Ha diterima, sehingga diartikan perceived ease of use (X1) memiliki pengaruh signifikan terhadap repurchase intention ( $Y$ ) pada konsumen Zalora. Temuan ini sesuai dengan hasil penelitian Thong et al. (2006), Chao et al. (2009)

b.Nilai $t$ hitung pada variabel perceived usefulness $\left(\mathrm{X}_{2}\right)$ adalah sebesar 6,061dengan tingkat signifikansi 0,000 . t hitung lebih besar dari t tabel yakni $(6,061>1.985)$ dan nilai signifikansi $0,000<0,05$ maka Ha diterima, sehingga diartikan perceived usefulness $\left(X_{2}\right)$ memiliki pengaruh signifikan terhadap repurchase intention $(Y)$ pada konsumen Zalora. Temuan ini sesuai dengan hasil penelitian Karahanna et al. (1999), Chao et al. (2009)

c. Nilai t hitung pada variabel trust $\left(X_{3}\right)$ adalah sebesar 8,316 dengan tingkat signifikansi 0,000 . t hitung lebih besar dari t tabel yakni $(8,316>1.985)$ dan nilai signifikansi $0,000<$ 0,05 maka Ha diterima, sehingga diartikan trust $\left(X_{3}\right)$ memiliki pengaruh signifikan terhadap repurchase intention (Y) pada konsumen Zalora. Hubungan antara kepercayaan dan niat untuk membeli kembali telah terdokumentasi dengan baik dalam literature (Anderson dan Weitz 1989, Reichheld dan Schefter 2000, Collier dan Bienstock 2006, Flavia'n dan Guinalı'u 2006).

d. Nilai $t$ hitung pada variabel perceived enjoyment $\left(\mathrm{X}_{4}\right)$ adalah sebesar 8,251dengan tingkat signifikansi 0,000. t hitung lebih besar dari t tabel yakni $(8,251>1.985)$ dan nilai signifikansi $0,000<0,05$ maka Ha diterima, sehingga diartikan perceived enjoyment $\left(\mathrm{X}_{4}\right)$ memiliki pengaruh signifikan terhadap repurchase intention $(Y)$ pada konsumen Zalora. Temuan ini sesuai dengan hasil penelitian Koufaris, (2002); Ahn et al. (2007).

\section{PENUTUP}

Penelitian ini merujuk pada hasil penelitian Chao et al. (2009) memberikan dasar rujukan yang penting dalam penelitian ini bahwa persepsi akan kemudahan, persepsi akan kemanfaatan, kepercayaan dan kesenangan yang dirasakan memiliki pengaruh positif dan signifikan pada niat membeli kembali. Sementara itu hasil penelitian ini menunjukkan hasil yang sama.

Dalam proses pembelian konsumen secara online, perceived ease of use (persepsi akan kemudahan) sangat penting. Situs website yang digunakan oleh Zalora dapat memberikan akses kemudahan untuk konsumen dalam hal melihat-lihat detail produk maupun untuk membeli sebuah produk. Pengaruh kuat dari persepsi akan kemudahan pada niat membeli kembali mungkin karena sifat konteks yang diteliti. Toko online sering membuat perubahan signifikan pada desain dan tata letak situs webnya selama periode waktu tertentu, dan dengan demikian pelanggan harus terusmenerus mengeluarkannya usaha agar bisa terbiasa dengan perubahan situs web

Zalora merupakan salah satu website yang dapat diakses dengan menggunakan sistem aplikasi online. Tidak hanya menggunakan web, tetapi Zalora dapat diakses 
dengan menggunakan aplikasi yang dapat diunduh di smartphone. Dengan adanya sistem aplikasi ini, Zalora dapat menyampaikan value yang berguna bagi konsumen. Karena kemudahan dalam pengaksesan dimana saja memberikan perceived usefulness (persepsi akan kemanfaatan), bagi konsumen.

Zalora merupakan suatu situs belanja berbasis online, trust (kepercayaan) menjadi hal yang sangat penting. Sistem website maupun aplikasi yang digunakan oleh Zalora dapat memberikan rasa kepercayaan kepada konsumen baik dalam hal privasi, kualitas dari produk yang ditawarkan, hingga barang yang sudah dibeli oleh konsumen. Terbukti dari sistem lacak pesanan yang dapat diakses oleh konsumen ketika sudah membeli produk di Zalora. lacak pesanan tersebut terdiri dari nomor order, tanggal order, detail barang, hingga status produk yang akan/sedang dikirim oleh produsen.

Persepsi akan kesenangan yang dirasakan (perceived enjoyment) yang diberikan Zalora kepada pelanggan meliputi kemudahan dalam penggunaan, kenyamanan, keamanan dalam bertransaksi, dan juga akan hal produk yang didapatkan ketika kita membeli di Zalora. Semua sesuai dengan apa yang tertera dalam website. Dengan manfaat yang diberikan kepada pelanggan sedemikian rupa, Zalora bertujuan untuk mendorong proses pembelian ulang.

Beberapa keterbatasan penelitian antara lain [1] Penelitian ini hanya meneliti kepuasan konsumen, harapan yang disesuaikan, nilai pelanggan dan persepsi akan kemanfaatan sebagai determinan niat untuk membeli kembali secara online. Jika melihat pada angka $\mathrm{R}$ square maka sebenarnya masih terdapat variabel lain yang tidak diteliti yang kemungkinan memiliki pengaruh terhadap minat untuk membeli kembali secara online. [2] Penelitian ini hanya fokus meneliti pelanggan Zalora di Jakarta. Dengan demikian hasil penelitian ini tidak dapat digeneralisir untuk industri retail (shopping online) pada umumnya.

\section{REFERENSI:}

Ahn, T., Ryu, S. and Han, I. 2007, The impact of web quality and playfulness on user acceptance of online retailing, Information \& Management, Vol. 44 No. 3, pp. 263-75.

Anderson, E. and Weitz, B.A. 1989, Determinants of continuity in conventional industrial channel dyads, Marketing Science, Vol. 8 No. 4, pp. 310-23.

APJII. 2017, Penetrasi dan Perilaku Pengguna Internet di Indonesia. diakses 4 April 2018 dari https://apjii.or.id/survei2017/download/87eYOsMF5JSriaw1ldkmZCBb2GEhxp

Babin, B.J. and Babin, L. 2001, Seeking something different? A model of schema typicality, consumer affect, purchase intentions and perceived shopping value, Journal of Business Research, Vol. 54 No. 4, pp. 8996.

Bart, Y., Shankar, V., Sultan, F. and Urban, G.L. 2005, Are the drivers and role of online trust the same for all web sites and consumers? A large-scale exploratory empirical study, Journal of Marketing, Vol. 69 No. 4, pp. 133-52.

Briliana Vita, NA Wahid, Y Fernando. 2015. The Effect of Motivation, Opportunity, Ability and Social Identity Towards Customer-to-Customer Online Know-How Exchange. Advanced Science Letters, Volume 21, Number 4, April 2015, pp. 819-822(4). https://doi.org/10.1166/asl.2015.5887

Briliana, Vita. 2016. Business-Oriented Social Networking Sites (B-SNS) Stickiness: Its Antecedents And Outcome On Intention to Purchase Apparel. South East Asia Journal of Contemporary Business, Economics and Law, Vol. 10, Issue 2 (Aug.) 
Briliana, Vita. 2017, Identifying Antecedents and Outcomes of Brand Loyalty: A Case of Apparel Brands in Social Media. Global Conference on Business and Economics Research (GCBER) 2017. 14-15 August 2017, Universiti Putra Malaysia, Malaysia

Briliana, Vita dan Nurwanti Mursito, 2017, Exploring antecedents and consequences of Indonesian Muslim youths' attitude towards halal cosmetic products: A case study in Jakarta. Asia Pacific Management Review, Volume 22, Issue 4, December 2017, Pages 176-184. https://doi.org/10.1016/j.apmrv.2017.07.0122

Chao-Min Chiu, Chen-Chi Chang, Hsiang-Lan Cheng, Yu-Hui Fang, 2009. Determinants of customer repurchase intention in online shopping, Online Information Review, Vol. 33 Issue: 4, pp.761784, https://doi.org/10.1108/14684520910985710

Clow, Kenneth E. and Donald Baack. 2016. Integrated Advertising, Promotion, and Marketing Communications. Pearson Prentice Hall.

Cyr, D., Head, M. and Ivanov, A. 2006, Design aesthetics leading to m-loyalty in mobile commerce, Information and Management, Vol. 43 No. 8, pp. 950-63.

Collier, J.E. and Bienstock, C.C. 2006, Measuring service quality in e-retailing, Journal of Service Research, Vol. 8 No. 3, pp. 260-75.

Davis, F. D. 1989, Perceived usefulness, perceived ease of use and users acceptance of information technology, MIS Quarterly, 13(3): 319-340

Flavia'n, C. and Guinalı'u, M. 2006, Consumer trust, perceived security and privacy policy: three basic elements of loyalty to a web site, Industrial Management \& Data Systems, Vol. 106 No. 5, pp. 601-20.

Hair, Joseph F, William C Black, Barry J Babin, and Rolph E Anderson. 2014. Multivariate Data Analysis. United Kingdom: Pearson Education Limited.

Karahanna, E., Straub, D.W. and Chervany, N.L. 1999, Information technology adoption across time: a crosssectional comparison of pre-adoption and post-adoption beliefs, MIS Quarterly, Vol. 23 No. 2, pp. 183213.

Keller, Kevin lane. 2013. Strategic Brand Management (Building, Measuring, and Managing Brand Equity). Pearson Prentice Hall.

Koufaris, M. 2002, Applying the technology acceptance model and flow theory to online consumer behavior, Information Systems Research, Vol. 13 No. 2, pp. 205-23.

Kotler, Phillip, \& Kevin Lane Keller. 2016. Marketing Management. 15ed Global edition. Pearson International Edition.

Koufaris, M. 2002, Applying the technology acceptance model and flow theory to online consumer behavior, Information Systems Research, Vol. 13 No. 2, pp. 205-23.

Lacey R, Morgan R M. 2009. Customer advocacy and the impact of B2B loyalty programs. Department of Management and Marketing, University of Alabama, Tuscaloo. J. Bus. Ind. Mark., 24(1): 3-13.

Marketeer. 2016. Memposisikan diri sebagai destinasi fesyen online terbesar di ASEAN, diakses 20 April 2016 dari http://marketeers.com/strategi-zalora-kembangkan-bisnis-di-indonesia/

Rajalie, Jimmy. dan Vita Briliana. 2014. Pengaruh Trust, Perceived Usefulness, Satisfaction dan Perceived Enjoyment Terhadap Online Repurchase Intention. Jurnal Bisnis dan Akuntansi, Vol. 16, HIm. 12 - 20

Reichheld, F.F. and Schefter, P. 2000, E-loyalty: your secret weapon on the web, Harvard Business Review, Vol. 78 No. 4, pp. 105-13.

Sekaran, Uma, and Roger Bougie. 2016. Research Methods for Business. United Kingdom: John Wiley \& Sons Ltd.

Sugiyono. 2016. Metode Penelitian Bisnis. Bandung: Alfabeta.

Thong, J.Y.L., Hong, S. and Tam, K. 2006, The effects of post-adoption beliefs on the expectation-confirmation model for information technology continuance, International Journal of Human-Computer Studies, Vol. 64 No. 9, pp. 799-810.

Venkatesh, V. and Davis, F.D. 2000, A theoretical extension of the technology acceptance model: four longitudinal field studies, Management Science, Vol. 46 No. 2, pp. 186-204. 
Wagner, Janet and Gabrielle Rydstrom. 2011, Satisfaction, trust and commitment in consumers' relationship with online retailers," in European Advances in Consumer Research, Vol. 5, ed. Andrea Groeppel-Klein and Franz-Rudolf Esch, Berlin, Germany: Association for Consumer Research, 276-81.

Wen, Chao, Prybutok, Victor.R. and Xu, Cheyan. 2011. An Integrated Model For Customer Online Repurchase Intention, The Journal of Computer Information Systems.

Lampiran Butir pertanyaan kuesioner

\begin{tabular}{cl}
\hline \multicolumn{1}{l}{ Perceived ease-of-use (persepsi akan kemudahan) } \\
\hline 1 & Belajar mengoperasikan websites Z mudah \\
2 & Websites Z dapat berinteraksi dengan flexible \\
3 & Berinteraksi dengan websites Z jelas dipahami \\
4 & Sangat mudah untuk menjadi terampil dalam mengoperasikan websites Z \\
5 & Websites Z mudah digunakan \\
\hline Perceived usefulness (persepsi akan kemanfaatan), \\
\hline 6 & Websites Z memudahkan mencari dan membeli barang untuk meningkatkan penampilan saya. \\
7 & Ketika mencari dan membeli barang di websites Z bisa meningkatkan produktivitas. (misalnya \\
& dalam waktu singkat saya bisa memilih beberapa barang sekaligus yang sedang saya \\
& butuhkan) \\
8 & Websites Z memberikan kemudahan untuk mencari dan membeli barang \\
9 & Websites Z meningkatkan efisiensi dalam mencari barang dan pembelian \\
10 & Websites Z berguna untuk mencari dan membeli barang yang dibutuhkan \\
\hline Trust (kepercayaan), \\
\hline 11 & Berdasarkan pengalaman saya merasa websites Z jujur \\
12 & Berdasarkan pengalaman saya merasa websites Z peduli tentang pelanggan \\
13 & Berdasarkan pengalaman saya merasa websites Z berpeluang yang baik \\
14 & Berdasarkan pengalaman saya merasa websites Z menepati janji \\
15 & Berdasarkan pengalaman saya merasa websites Z dapat dipercaya \\
16 & Berdasarkan pengalaman saya merasa websites Z transaksi akan berhasil \\
\hline Perceived enjoyment (persepsi akan keterlibatan) \\
\hline 17 & Senang berinteraksi di websites Z \\
18 & Menggunakan websites Z untuk membeli menimbulkan kesenangan \\
19 & Membeli produk di websites Z menarik \\
\hline Repurchase intention (niat membeli kembali) \\
\hline 20 & Ingin terus membeli produk di websites Z \\
21 & Kemungkinan besar saya akan terus membeli produk di websites Z \\
22 & Berniat untuk terus membeli produk di websites Z dimasa mendatang \\
\hline
\end{tabular}

